Control and Operation of Cable Telegraphy.

THE success of short-wave radio telegraph 'links' during recent years is well known to have led to the merging of the most important of the cable and radio companies. In addition, the rapid strides made in radio telegraphy and in international telephony have produced the impression that submarine cable telegraphy is now of little value. In a paper read to the Institution of Electrical Engineers on Jan. 7 by $\mathrm{H}$. Kingsbury and R. A. Goodman on cable telegraphy, it is stated that there are no signs of the supersession of transoceanic cable telegraphy by radio, due to economic or other reasons. The growth of cable communications between the countries of Europe and the rest of the world is both steady and satisfactory.

UNFORTUNATELY, it has always been the general policy of the European States to retain not only the control but also the actual operation of their telephone systems. Hence at the international meetings the majority of the delegates are merely representative of the interests of their governments. The immediate revenue accruing to the State rather than the development of a first-class foreign telegraph service is their main consideration. It is therefore difficult to introduce reforms, no matter how desirable they seem to the engineers of private companies. Cable companies could easily compete with the direct radio beam, provided that the companies had control of all stations and that land lines were available and properly maintained. Many minutes are added to the transmission time of a message by the mere handing over of traffic from a company to a government system. For example, a preferred rate message from San Francisco to Copenhagen handed in over the counter in the ordinary way occupies about fifteen minutes from the time it passes out of the sender's sight until it is in the hands of the addressee. On the other hand, a sender offering a short telegraph message by telephone in New York for London is reasonably certain of delivery in two minutes from the moment of complet. ing dictation of the message in New York.

\section{Weather of 1931.}

IN a pamphlet entitled "Notes on the Weather of 1931", issued by the Meteorological Office (Air Ministry), the topsy-turvy character of last year's weather is clearly brought out. New ' records' for cold were set up in March and October, months that are only on the fringe of winter and sometimes provide summer warmth. On March 3 temperature fell to $1^{\circ} \mathrm{F}$. at Braemar, and on March 10 to $5^{\circ} \mathrm{F}$. at Rickmansworth. On the latter date temperature failed to rise above $30^{\circ}$ during the day in many places in south-east England. The night frosts of the last week of October were in some parts of England the most severe ever recorded in that month. There was a pronounced tendency for the worst weather in the south-east of England to be reserved for week-ends and public holidays, and the August holidays provided some days that were much colder than those experienced at Christmas. The gale in the English Channel on Aug. 24 would have been noteworthy had it occurred in mid-winter. No temperature within three degrees of the reading of $61^{\circ}$ that was recorded at Aberdeen on Christmas Eve has ever been known there in December for at least sixty years. Mention should be made also of the very rare event of a tornado of the American type, on June 14, at Birmingham. Although not to be compared with the worst tornadoes experienced in America, this storm was violent enough for roofs to be stripped, and there was loss of life. The zone of destruction was, fortunately, a characteristically narrow one, varying from 200 yards to 800 yards. The year must be regarded meteorologically as one of the most eventful known since the Meteorological Office was inaugurated nearly eighty years ago.

\section{Prehistoric Stock of South Africa.}

Ar a meeting of the Royal Anthropological Institute (Section of Human Biology) on Jan. 8, Sir Arthur Keith exhibited a series of human skulls from the Matje River Rock Shelter, a newly discovered prehistoric site in the Zitzikamma District, on the coast of the Cape Province. The deposits in this rockshelter, amounting to 21 feet in depth, were excavated by Prof. T. F. Dreyer, of Grey University College, Bloemfontein. The rock-shelter was first inhabited during the age of the 'Mossel Bay' culture, which is usually equated with one of the later palæolithic cultures of Europe, and this culture was richly represented during the formation of the deeper strata, amounting in depth to 14 feet. All the remains from the Mossel Bay strata manifest racial traits, which were first revealed by the discovery of the largebrained Boskop skull in 1913. Three of the skulls from the deepest Mossel Bay strata have peculiar features of the forehead; the frontal bones appear compressed from side to side, with a high median keel. This malformation, known as trigonocephaly, occurs occasionally in modern races. A tendency to trigonism is not uncommon among Bushmen and Hottentots, who may be regarded as descendants of the prehistoric stock of South Africa. Sir Arthur Keith added that South Africa was the home of the most remarkable of all prehistoric peoples known to us, a people or stock tending to produce individuals with brains of remarkable dimensions and with a tendency for infantile and juvenile characters to persist into adult life, a tendency which Prof. M. R. Drennan has termed 'pedomorphism'. Although remains of Bushmen have been found so far north as Lake Nyassa and Boskop remains in Northern Rhodesia, all the evidence at present points to South Africa as the evolutionary home of this prehistoric pedomorphic race.

\section{Prehistoric Gold Ornaments from Cornwall.}

Two torques and six penannular armlets have been found by a farm labourer in a bank of earth on Amalveor Farm, in Towednack, near St. Ives, Cornwall. According to the Times for Jan. 2, one of the torques consists of three strips of twisted metal ; the other, a single twisted coil, is of considerable length, its circle being $13 \mathrm{in}$. in diameter, and, being flexible, 
it may have been worn twined several times round the neck or waist. Both have the ends bent back to form the familiar interlocking hook. Of the armlets four are simple metal rods; the remaining two are heavier, one being hexagonal and the other lozengeshaped in section. The find is assigned to the middle or late bronze age; but it is to be noted that the simple armlets do not show the thickening of the wire at the ends characteristic of the developed type of armlet, which, in the British late bronze age, expanded into the cup-shaped terminals.

THE number, character, and distribution of finds of prehistoric gold ornaments in Cornwall, of which that of a lunula, or crescent-shaped gold neck ornament, associated with a flat axe found at Harlyn Bay is the best known, would suggest that intercourse with Ireland, the undoubted source of these omaments, began early, possibly at the very beginning of the bronze age, and was extensive. Not only did Cornwall provide tin, in which Ireland was poor, but it served as a stage in the voyage to Brittany and Iberia. Close intercourse between Ireland and Cornwall lasted well into Christian times, as is shown by the legends of the Cornish saints, though their many obviously mythical details point to a much earlier tradition. It is to be hoped that lack of funds will not stand in the way of the proposed excavation of the site on which this latest find was made. If it should prove a habitation site, as is conjectured, it should furnish much needed evidence corroborative of the dating of Cornish gold ornaments.

\section{American Patent Law System.}

UNDER the auspices of Science Service, Dr. E. J. Prindle gave, on Nov. 13, a radio talk on the American patent law system. He pointed out how backward agriculture and manufacturing were prior to the introduction of the patent system, which gave the inventor the exclusive right for seventeen years to make, use, and scll his invention. So great is the transformation made by the introduction of machinery, that in garnering wheat crops one man can, by its use, do the work formerly requiring ten men. Only one man is now required for every 250 acres. The making of agricultural machinery is a very large industry. The expense of developing a single invention often runs into hundreds of pounds, and sometimes, as in the case of tho Curtis stcam turbine, into hundreds of thousands of pounds. Without the possibility of recovering this sum and making a profit on the invention, neither individuals nor companies can afford to make and perfect inventions. Without the patent law, Edison could not have accomplished his great work which has benefited humanity. In connexion with electric lighting alone, Edison took out 375 patents. As a patent for an invention gives a monopoly, some think that it is therefore harmful, as many monopolies undoubtedly are. But a patent only gives an inventor a monopoly of that which he creates; it takes nothing from the public, and at the end of seventeen years the public receives the invention free. In normal times, the patent system has greatly increased the field of employment.

No. 3246, VoL. 129]

\section{Hawks as Decoys.}

MARTIAL's epigram on the hawk (Book 14, 216) has been taken as an indication that falconry was practised by the classical ancients; but as the hawk here deceives (decipit) the birds, it would seem rather as if it were used, like an owl, as a decoy to entrap birds coming to mob it ; and in the Field for Dec. 26, 1931, Col. Nawab Malik Sir Umar Hayat Khan, in writing on falconry, indicates a similar practice in modern India; for he says that if a sparrow-hawk be kept under a net or in a cage and nooses made around, and the receptacle put where 'seven sisters' are common, these birds (the common Indian babbler Turdoides terricolor) can be caught by the dozen. Being weak flyers, they are particularly likely to be attacked by hawks, but being also sociable and strong in beak and claws, they often succeed in rescuing the bird attacked, so that the hawk is an enemy with which they contend on more or less equal terms. The use of the captive hawk as a decoy, however, is no more falconry than is the employment of wild hawks in fowling by bribing them to "wait on' and make birds lie, a practice also followed in classical times and in India and Argentina in our day, when the former country is still the stronghold of the perfected art.

\section{Statistics of Cancer in East London.}

THE Ministry of Health has issued a report by Dr. Janet Forber (née Lane-Claypon) dealing with incurable cases of cancer in east London (Reps. on Pub. Health and Med. Subjects, No. 66. H.M. Stationery Office. 1s. net). There appears to be no shortage of medical and nursing care and hospital accommodation for these patients. The sample of 1983 cases investigated brings out (as other investigations have done) a contrast in sex incidence of the disease, namely, the great preponderance of cancer of the lip, tongue, mouth, pharynx, and larynx in the male, and cancer of the reproductive organs in the female. The mean age at death is low for fatal cancer of the uterus, ovary, and, in both sexes, the lung and pleura, and high for fatal cancer of the skin and prostate. The mean duration of in-patient care for those who seek hospital treatment is only 2.28 months, being less than one month for 46 per cent, suggesting that the terminal and troublesome stage of fatal cancer is, happily, of short duration.

\section{Researches in Chemical Engineering.}

WE have received the Proceedings of the Chemical Engineering Group, Society of Chemical Industry, vols. 11 and 12, 1929 and 1930 (in one volume). This contains a number of valuable papers, dealing with such subjects as surface energy, flotation, water treatment, alloy steels, gas and electric heating furnaces, and welding. The standard of the papers is high, and they are usually followed by interesting discussions. The Transactions of the Institution of Chemical Engineers, vol. 8, 1930, has also been received, and contains important papers on various subjects related to chemical engineering, such as cellulose products, crystallisation, high pressure reactions, tannery waste, wood pulp, pulverised fuel, and the recovery of metals from waste materials. Both these volumes are very 